\title{
Is it ethical to use drospirenone-containing combined oral contraceptives?
}

This Journal recently published a review of the thrombogenic risk associated with drospirenone (DRSP)-containing combined oral contraceptives (COCs). ${ }^{1}$ The same issue has recently been addressed by the Food and Drug Administration (FDA). Like other studies the FDA study reported that the use of DRSP-containing COCs was associated with an increased risk of venous thromboembolism (VTE) as compared to levonorgestrel (LNG)containing COCs [incidence rate ratio: all users 1.49 (95\% CI 1.19-1.8), new users 1.48 (95\% CI 1.07-2.05)]. ${ }^{2}$

While epidemiological studies find it difficult to show causality they provide useful information on which to base clinical practice. Clinical decision-making has to be ethical. Beauchamp and Childress $^{3}$ set out the most commonly applied framework in Western bioethics. They base their 'four principles' on common morality, a set of rules that is shared by all ethically acting individuals and not just ethical saints. Their four principles of ethical practice are: autonomy, beneficence, non-maleficence and justice.

To respect patient autonomy we need to provide sufficient information for the patient to form her own opinion as to the benefit or harm of a specific intervention. 
She cannot give consent unless the consent is informed. A patient who requests or is about to receive COCs containing DRSP has to understand that there may be an increased risk of VTE as compared to other COCs. [Indeed, this is stated in the UK Medicine and Healthcare products Regulatory Agency's guidance on Yasmin ${ }^{\circledR]}$.

Beneficence refers to actions that serve the best interest of the patient. While there is some evidence that DRSP-containing COCs are better for some patients than other COCs, in most cases there is little difference between COCs in terms of effectiveness and side effects. ${ }^{4}$

Non-maleficence, also understood as the 'precautionary principle' (primum non nocere), stipulates that we should use interventions that have the least potential to do harm. When choosing between interventions we do not need to be certain that one intervention is more dangerous than the other: a well-founded suspicion provides an adequate reason for us to act with caution.

Recently the Advisory Committee members of the FDA voted 15 to 11 that "in the general population of women who desire contraception, the benefits of the DRSP-containing oral contraceptives for prevention of pregnancy outweigh their risks". ${ }^{5}$ In other words, a large minority on the FDA review panel felt that DRSPcontaining COCs are not worth the risk. This should provide sufficient doubt to activate the precautionary principle, particularly as potentially safer alternatives exist.

Justice refers to the just use of health care resources and achieving the highest level of health given the available resources. As DRSP-containing COCs are significantly more expensive then LNG-containing COCs the use of the more expensive COC can only be justified if it achieves a higher level of health for the patient taking it. This may be the case in a small proportion of women on COCs but generally is unlikely.

Providers have the right to refuse a treatment requested by the patient. We decline treatment for erectile dysfunction (ED). Although ED can lead to a significant reduction in the quality of life and can be treated effectively with safe medication we argue that this is not the best use of resources. Similarly we may need to decline other requests.

Prescribing DRSP-containing COCs may be ethical in specific circumstances where fully informed patients have conditions known to respond better to DRSP-containing COCs than to LNGcontaining COCs; otherwise prescribing a more expensive and potentially less safe drug may not be best practice.
Rudiger Pittrof, MRCOG, MFSRH

Consultant in Genitourinary Medicine, Sexual Health, St Thomas' Hospital, London, UK; Rudiger.Pittrof@gstt.nhs.uk

Competing interests None.

J Fam Plann Reprod Health Care 2012;38:205-206. doi:10.1136/jprhc-2012-100344

\section{References}

1 Dinger J, Shapiro S. Combined oral contraceptives, venous thromboembolism, and the problem of interpreting large but incomplete datasets. J Fam Plann Reprod Health Care 2012;38:2-6.

2 Ouellet-Hellstrom R, Graham DJ, Saffa JA. Combined Hormonal Contraceptives (CHCs) and the Risk of Cardiovascular Disease Endpoints (CHC-CVD Final Report 111022v2). http:// www.fda.gov/downloads/Drugs/DrugSafety/ UCM277384.pdf [accessed 12 January 2012].

3 Beuachamp TL Childress JF. Principles of Biomedical Ethics (6th edn). Oxford, UK: Oxford University Press, 2009.

4 Lawrie TA, Helmerhorst FM, Maitra NK, et al. Types of progestogens in combined oral contraception: effectiveness and side-effects. Cochrane Database Syst Rev 2011;5:CD004861.

5 Mechcatie E. FDA Panel Reviews VTE Risk Drospirenone-Containing OCs Family Practice News. http://www.familypracticenews.com/ news/more-top-news/single-view/fdapanel-reviews-vte-risk-drospirenonecontaining-ocs/9ce4d7fab5.html [accessed 12 January 2012]. 